NBSIR 83-2752(R)

\title{
Advanced Mass Calibration in State Laboratories
}

U.S. DEPARTMENT OF COMMERCE

National Bureau of Standards

Center for Absolute Physical Quantities

Washington, DC 20234

August 1983

Sponsors Report

Prepared for:

U.S. DEPARTMENT OF COMMERCE

- QC National Bureau of Standards

Office of Weights and Measures

.456

Washington, DC 20234 
NBSIR 83-2752

\section{ADVANCED MASS CALIBRATION IN STATE LABORATORIES}

Randall M. Schoonover

U.S. DEPARTMENT OF COMMERCE

National Bureau of Standards

Center for Absolute Physical Quantities

Washington, DC 20234

August 1983

Sponsors Report

Prepared for:

U.S. DEPARTMENT OF COMMERCE

National Bureau of Standards

Office of Weights and Measures

Washington, DC 20234

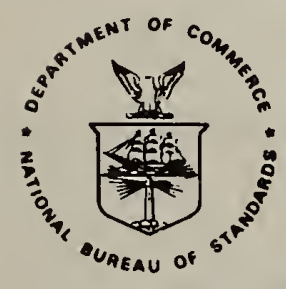

U.S. DEPARTMENT OF COMMERCE, Malcolm Baldrige, Secretary NATIONAL BUREAU OF STANDARDS, Ernest Ambler, Director 



\title{
ADVANCED MASS CALIBRATION IN STATE LABORATORIES*
}

\author{
R. M. Schoonover \\ Center for Absolute Physical Quantities \\ National Bureau of Standards \\ Washington, D. C. 20234
}

\section{ABSTRACT}

This report describes the initial phase of a development program to improve maintenance of mass reference standards in State Weights and Measures Laboratories. Four one-kilogram objects of special design were calibrated by five State Laboratories, a highly qualified "check" laboratory, and NBS. The results indicate that certain improvements should be made in critical areas of the recalibration process. Errors associated with air buoyancy correction, for example, are significant; for this reason, it is necessary to improve the methods and instrumentation used for the measurement of air pressure, air temperature, and relative humidity in State Laboratories. Proposed future work is focused upon the air buoyancy correction, the simplification of calculation procedures, and the provision of NBS Reference Standards to improve the values assigned to the State Reference Standards.

The work reported was based upon the collaboration of the NBS Length and Mass Measurements and Standards Division, the NBS Office of Weights and Measures, Sandia Laboratories, and the five participating State Laboratories.

*This report includes privileged information and it is intended for internal NBS use only. 


\section{$\underline{\text { PURPOSE }}$}

Recent measurement control programs coordinated by the Office of Weights and Measures have disclosed some apparent anomalies in mass measurements in State programs that may be the result of inconsistencies in the mass standards that are in the possession of the State laboratories. The measurements reported here were designed to detect problems that would be encountered if the State laboratories were given the opportunity to perform measurements necessary to recalibrate State reference standards for mass and to determine the techniques that should be developed to perform this task most effectively.

METHOD

A. General

A weighing scheme has been devised using four one-kilogram weights, some with special features, to examine the following aspects of the participating State laboratories:

1. The accuracy of the State Kilogram Mass Standards

2. Laboratory techniques and environmental influences on assigned values

3. Adequacy of the required instrumentation

4. Data reduction difficulties and degree of automation

Cleaning of test weights by State Laboratories was specifically excluded from the measurement procedures.

In the measurement sequence, Division 523 cleaned the weights by vapor degreasing and calibrated the circulating weights before and after calibration by each State. This procedure enables early detection of a mass change in any weight due to accident or mistreatment. 
Fives states participated in the measurements:

1. California

2. Colorado

3. Nevada

4. New York

5. Utah.

Sandia laboratory also participated at the request of NBS in order to provide Division 523 with additional measurement confirmation in areas for which the associated instrumentation is critical to success. Unlike most State 1aboratories, the Sandia laboratory maintains a high level of competence in pressure and temperature measurements that are important in mass calibrations involving significant buoyancy corrections.[1]*

B. The measurement format

Each participating laboratory was asked to assign mass values to the four one-kilogram test weights by comparison with its primary kilogram standards using a specified format. The four weights, designated $\mathrm{A} 1, \mathrm{~S} 2, \mathrm{R} 2$, and $\mathrm{H} 2$ were paired as follows:

$$
\begin{array}{lll}
\text { Pair 1 } & \text { A1 } & \text { S2 } \\
\text { Pair 2 } & \text { R2 } & \text { H2 }
\end{array}
$$

Each pair was to be calibrated by performing all possible comparisons with the two State kilogram standards. This procedure yields a total of six intercomparisons per pair, shown in table $\mathrm{I}$, which were to be accomplished by the method known as double substitution weighing. Air density parameters were observed at the beginning and end of the sequence involving pair 1 and during the third and sixth observations for pair 2. The sequence of observations was modified for pair 2 to insure that air density parameters were noted during the most sensitive comparisons 
(see table I). State metrologists were not given special instructions concerning the measurement of the air density parameters: temperature, barometric pressure, or relative humidity.

\section{THE ARTIFACTS}

The NBS mass standards used by Division 523 (B1, D2) for the NBS measurements were manufactured by the Troenmer Co. in the late 1960's. These weights are made of highly polished stainless steel with height nearly equal to diameter. Each weight is constructed as one-piece with an integral lifting knob machined into the object. Each State onekilogram standard is also made from one piece of stainless steel with height nearly equal to diameter. However, lifting is provided by a pinched waist, i.e., "hour glass shape". The State standards were manufactured by several firms from an alloy of nominal density $8.0 \mathrm{~g} / \mathrm{cm}^{3}$ furnished by NBS.

The package sent to each State contained four one-kilogram weights. The test weight designated Al is identical to the NBS standards described above (B1, D2). Weights S2, R2, and H2 were specially manufactured by Division 523 from stainless steel and were designed with highly unusual features to detect various weighing errors. S2 is a weight made from three concentric tubes supported by a tee-shaped base for simultaneous lifting of the individual pieces. This weight has an extremely large surface area. Weight R2 is a thick-walled tubular weight with a surface area which approximates that of $\mathrm{H} 2$. $\mathrm{H} 2$, although made of stainless steel, is a hermetically sealed hollow weight of average density $2.9 \mathrm{~g} / \mathrm{cm}^{3}$ and, consequently, it has a much larger volume than R2. Table II lists the important artifact characteristics. 


\section{DATA REDUCTION}

The instructions supplied to each State contained the information required to perform a complete data reduction and assignment of the mass values to the four one-kilogram weights. These instructions included:

1. Least-squares matrix coefficients

2. Standard deviation calculation for the least-squares fit

3. Volumes and thermal expansion coefficients of the weights

4. Fractional weight calibration report for the weight set supplied in the package

5. Air density formula.

Each State was also asked to return the raw data to NBS with sufficient information to permit the use of the NBS 1182 computer and the mass code[2] for data reduction.

\section{$\underline{\text { RESULTS }}$}

Each laboratory completed the measurements and reduced the data according to the instructions provided by NBS. The results varied in detail for many reasons including round-off errors attributed to hand calculators and the omission of thermal expansion corrections. Two laboratories made mathematical errors in the data reduction and were given the opportunity to correct them. The results of the State calculation, although not used, are given in table IV. These data indicate that most states had problems calculating the mass of $\mathrm{H} 2$ as compared to the NBS calculated values.

Table III presents the NBS reduced values assigned to the artifacts, the series standard deviations, and corresponding $F$ ratios, check 
standard agreement, and $T$ values. For the moment, consider the check standard values. Each series was solved based on the value of a single kilogram standard and not the sum of the two standards as is the usual method. The value assigned to the second kilogram standard, referred to here as the "check standard," is compared to its "accepted value" and any difference is given in the appropriate columns of table III. Based on the statistical " $T$ " test, all values except one are within the measurement error limits. Of course, if the Standard and check standard change mass an equal amount, the difference would remain constant and incorrect mass values would evade the check.

All States performed the weighings on balances of the same make and model; Sandia and NBS have more modern models that in principle and performance, however, do not differ significantly from those belonging to the State laboratories. Standard deviations (Series S.D. in table III) for these instruments are given for each weight pairing. Experience with balances of this type indicates that a $60 \mu \mathrm{g}$ standard deviation is quite normal and better than the manufacturer's specifications. The calibration data are in agreement with this experience and indicate that all balances functioned normally during these measurements.

NBS assigned seven values to each weight before shipment and upon return from each laboratory. Prior to each calibration, all weights were vapor degreased and allowed several days to equilibrate. At least 24 hours before calibration the weights and standards were stored in an annex to the balance case to allow for further temperature equilibration. In table III the mean values for each of the weights are given with the corresponding standard deviations. The standard deviation values are typical of the methods and instrmentation used in these measurements. 
It is useful to look at the mass values assigned by each participating laboratory by examining the differences between these values and the NBS mean value, as shown in table V. The reader should keep in mind that weights $\mathrm{A} 1, \mathrm{~S} 2$, and R2 have nearly the same volume as the standards (see table I) and therefore most of the buoyant force is self-cancelling. Weight A1 closely resembles the standards in every way whereas S2 has a much larger surface area and it should be relatively more sensitive to surface related problems.

Using the range of values for $\mathrm{A} 1$ as a normal reference, it may be noted that the ranges of values for S2 and R2 are significantly larger; that is most likely caused by the thermal sensitivity of the weight geometry. The range of values assigned to weight $\mathrm{H} 2$ is much larger than the ranges for the other three weights. Moreover, the mean values assigned to $\mathrm{H} 2$ by the States show a large offset from the corresponding NBS value whereas the mean values of the other weights agree well within the uncertainty limits discussed in the next section. Although we could expect thermal problems to cause weight $\mathrm{H} 2$ to behave similarly to $\mathrm{S} 2$ and $\mathrm{R} 2$, additional errors in the buoyancy correction due to the lower average density of $\mathrm{H} 2$ are dominant here. With the techniques used by NBS and Sandia in this work the agreement between NBS and Sandia is typical of the agreement we should expect for a weight such as H2[3]. In summary, it is evident that a somewhat smaller range in the assigned values for weights $\mathrm{A} 1, \mathrm{~S} 2$, and R2 could be economically achieved by the States with improved thermal control. Improvements in the range of assigned values for weights such as $\mathrm{H} 2$ will require significant improvements in the capability of States to measure air temperature, pressure, and relative humidity. These and other improvements are discussed in the last section of this report. 


\section{UNCERTAINTY ESTIMATES}

Before the beginning of this program, the NBS standards B1 and D2 used in this work were suspected to have lost mass. A recent comparison with the platinum prototype kilograms does indicate a mass loss of 76 and 40 micrograms, respectively. It is also known that the two NBS working kilograms originally used in the calibration of all the State one-kilogram standards have changed. However, there are two partially compensating effects: mass is increasing from the lack of cleaning and, at the same time, there is a mass loss from abrasion that occurs with use. Therefore at this time it is premature to place realistic uncertainties on the accuracy of the measurements reported here. However it is possible to estimate a limit for the offset between the State kilograms and the NBS standards used in this work.

Recent recalibration of the NBS working kilograms that were initially used to calibrate the State kilograms (not B1 and D2) indicates a mass loss of 100 micrograms from the accepted value. In the early 1970's other measurements indicated that even larger departures from the accepted values could have been possible when the working standards were relatively clean. Therefore, there might be an offset between the State assigned weight value for weight $A 1$ and the value assigned by NBS. At most, due to this cause, the State values should not be in disagreement with values assigned to A1 by NBS by more than 125 micrograms. Normally the uncertainty of weights such as A1, as assigned from a "four ones series" (see table I) where the restraint is a pair of standard kilograms is, in general

$$
\text { Uncertainty }=3(0.6124 \times \text { S.D. })+\text { S.E. }
$$


where S.E. is the systematic error for the standards and S.D. is the standard deviation of the least squares adjustment. For an ordinary one-kilogram NBS calibration this amounts to about $100 \mu \mathrm{g}$ but it can vary with the balance used to make the measurement. For most of the participating l.aboratories an estimate based on the NBS calibration certificate for a State standard would be

$$
3(0.6124 \times 60)+100=210 \mu \mathrm{g} .
$$

\section{FUTURE DIRECTION}

There are two areas that must be improved to advance this project. The first priority is to reduce the work load on the staff of Division 523 and the State metrologists and the second priority is to recalibrate the State one-kilogram standards with improved techniques. The first priority will be met by reducing the number of measurements made at NBS and by shipping a portable microcomputer with data reduction software as a part of the weight package so that each participant can reduce the data using validated methods in his own laboratory.

Other improvements that will be made in future measurements include: a prescribed procedure for thermal conditioning of the weights, the addition of calibrated air density instrumentation in the weight package and the addition of two one-kilogram standard masses that will enable the States to recalibrate their one-kilogram standards.

\section{ACKNOWLEDGMENTS}

The author is indebted to A. Tholen and Henry Opperman of Division 120 for their support and interest in this project. 

Table I

The sequence of observations known as a "four ones series" [4] for both pairs of artifacts calibrated by the State participants in terms of their standards.

\begin{tabular}{|c|c|c|c|c|c|}
\hline \multirow{2}{*}{$\begin{array}{l}\text { OBSERVATION } \\
\text { ORDER }\end{array}$} & \multirow{2}{*}{$\begin{array}{l}\text { OBSERVED } \\
\text { DIFFERENCE }\end{array}$} & \multicolumn{4}{|c|}{ KILOGRAMS PAIR 1} \\
\hline & & STATE 1 & STATE 2 & $\mathrm{~A} 2$ & S2 \\
\hline $1^{*}$ & 1 & + & - & & \\
\hline 2 & 2 & + & & - & \\
\hline 3 & 3 & + & & & - \\
\hline 4 & 4 & & + & - & \\
\hline 5 & 5 & & + & & - \\
\hline \multirow[t]{3}{*}{$6^{*}$} & 6 & & & + & - \\
\hline & & \multicolumn{4}{|c|}{ KILOGRAMS PAIR 2} \\
\hline & & STATE 1 & STATE 2 & $\mathrm{R} 2$ & $\mathrm{H} 2$ \\
\hline 1 & 1 & + & - & & \\
\hline 2 & 2 & + & 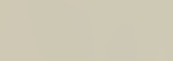 & - & \\
\hline 4 & 3 & + & . & & - \\
\hline $3 *$ & 4 & & + & - & \\
\hline 5 & 5 & & + & & - \\
\hline $6 *$ & 6 & & & + & - \\
\hline
\end{tabular}

*Air density parameters recorded. 
Table II

Artifact Characteristics

\section{KILOGRAM}

DESIGNATION

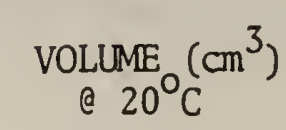

127.3852

127.6250

$125 *$

$125 *$

127.384

126.545

126.392

337.666
ASSUMED THERMAL

COEFFICIENT

CUBIC (ppm)

\section{APPROXIMATE SURFACE AREA $\left(\mathrm{cm}^{2}\right)$}
A1
S2

R2

$\mathrm{H} 2$

45

45

45

45

45

45

45

45
145

145

145

145

145

660

270

270

*Assumed based on nominal mass and a density of $8.0 \mathrm{~g} / \mathrm{cm}^{3}$ at $20{ }^{\circ} \mathrm{C}$. 


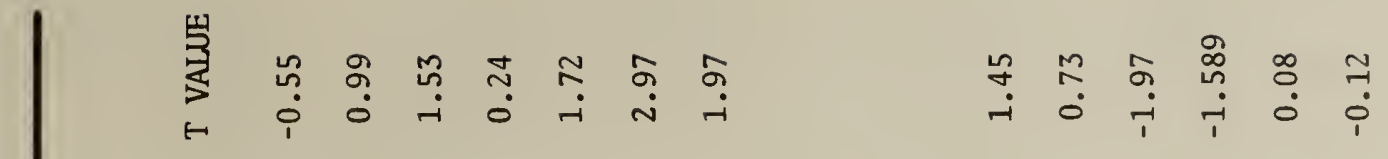

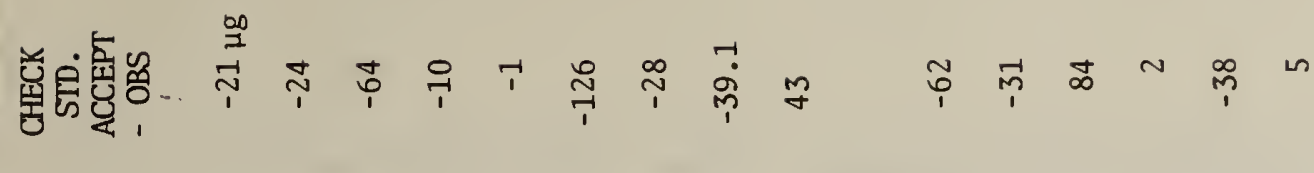

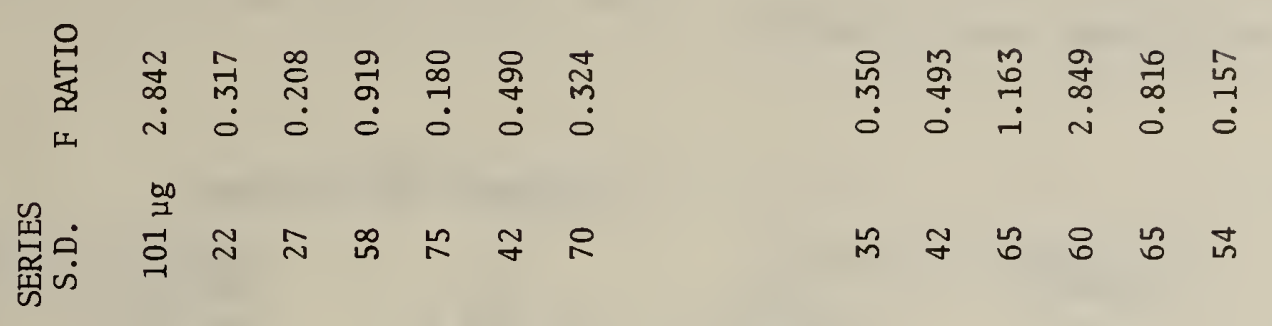

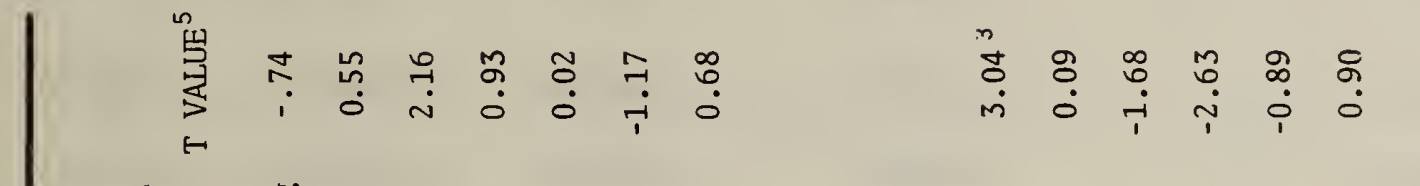

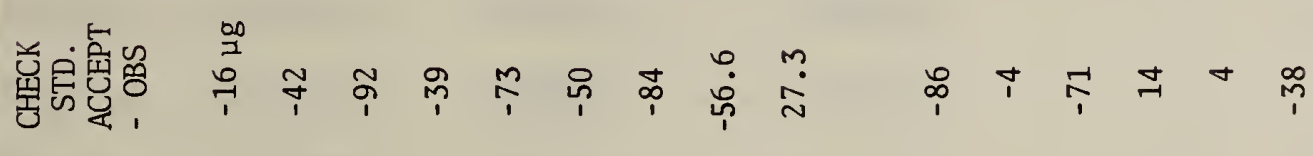

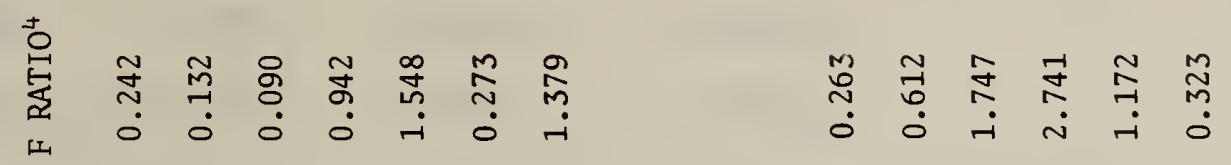

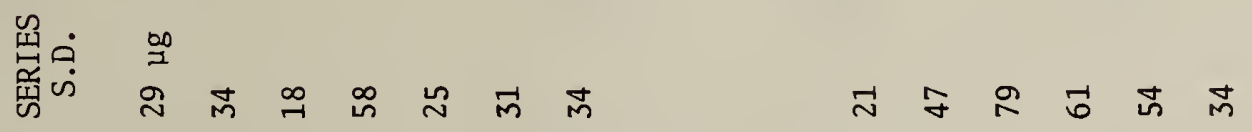

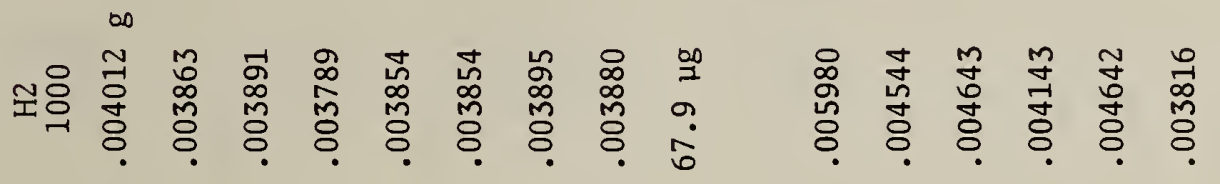

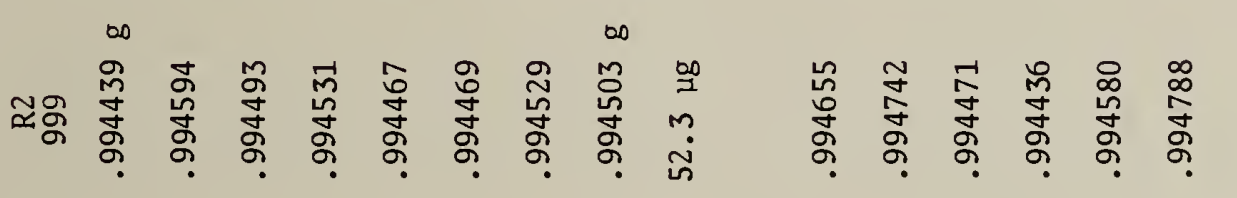

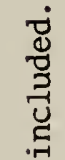


Table IV

State participants data reduction.

\begin{tabular}{|c|c|c|c|c|}
\hline \multirow[b]{2}{*}{ Kilograms: } & \multicolumn{4}{|c|}{ Assigned Mass Values } \\
\hline & $\mathrm{A} 1$ & S2 & $\mathrm{R} 2$ & $\mathrm{H} 2$ \\
\hline & $1000 \mathrm{~g}$ & $999 \mathrm{~g}$ & $999 \mathrm{~g}$ & $1000 \mathrm{~g}$ \\
\hline New York & .009302 & .988628 & .994656 & .005920 \\
\hline California & .009303 & .988787 & .994744 & .004497 \\
\hline Nevada & .009107 & .988485 & .994433 & .004384 \\
\hline Colorado & .009076 & .988551 & .994543 & .003347 \\
\hline Utah & .009244 & .988679 & .994780 & .004115 \\
\hline
\end{tabular}


Table V

NBS values minus participant values (as calculated by Division 523)

LABORATORIES IN MEASUREMENT ORDER

New York

California

Nevada

Sandia

Colorado

Utah

$\overline{\mathrm{X}}$

RANGE

\section{KILOGRAM DESIGNATION}

A1

S2

R2

$\mathrm{H} 2$

$-163 \mu \mathrm{g} \quad-72 \mu \mathrm{g}$

$-152 \mu \mathrm{g} \quad-2100 \mu \mathrm{g}$

$-169$

$-236$

$-239$

$-664$

62

77

32

$-763$

30

$-186$

67

$-263$

64

$-49$

$-77$

$-762$

285

64

$-136$

$-14$

$-748$

$-47$

$-100$

524

2164 
REFERENCES:

1. F. E. J. Jones, Res. Nat. Bur. Stand. (U.S.) 83, 419 (1978).

2. R. N. Vainer and R. C. Raybold, "National Bureau of Standards Mass Calibration Computer Software," NBS Technical Note 1127 (July 1980).

3. R. M. Schoonover, R. S. Davis, R. G. Driver and V. E. Bower, J. Res. NBS 85, 27 (Jan-Feb 1980).

4. J. M. Cameron, et al., "Designs for the Calibration of Standards of Mass," NBS Technical Note 952 (June 1979). 


\begin{tabular}{|c|c|c|}
\hline $\begin{array}{l}\text { U.s. DEPT. OF COMM. } \\
\text { BIBLIOGRAPHIC DATA } \\
\text { SHEET (See in structlons) }\end{array}$ & $\begin{array}{l}\text { 1. PUBLICATION OR } \\
\text { REPORT NO. }\end{array}$ & 2. Performlns Organ. Report Nod 3. Publlcation Date \\
\hline
\end{tabular}

4. TITLE AND SUBTITLE

Advanced Mass Calibration in State Laboratories

5. $A \cup T H O R(S)$

R. M. Schoonover

6. PERFORMING ORGANIZATION (If joint or other than NBS, see instructions)

NATIONAL BUREAU OF STANDARDS

DEPARTMENT OF COMMERCE

WASHINGTON, D.C. 20234

9. SPONSORING ORGANIZATION NAME AND COMPLETE ADORESS (Street, City, Stote, ZIP)

7. ContractGrant No.

8. Type of Report \& Period Covered

10. SUPPLEMENTARY NOTES

Document describes a computer program; SF-185, FIPS Software Summary, is attached.

11. ABSTRACT (A 200-word or less foctual summary of most significant information. If document includes a slgnificant bibliography or literature survey, mention it here)

This report describes the calibration of four one-kilogram objects by five State laboratories. The project is of mutual interest to the Length and Mass Measurements and Standards Division (523) and to the Office of Weights and Measures (120). The work is ongoing at the present time, however, the initial phase is completed and reported here. Also discussed is the proposed direction of future work.

12. KEY WORDS (Six to twelve entries; alphabetical order: capitalize only proper names; and separate key words by semicolons) Air density; combinational weighing; mass; uncertainty; weighing.

Unlimited

$\square$ For Official Distribution. Do Not Release to NTIS

$\square$ Order From Superintendent of Documents, U.S. Government Printing Office, Washington, D.C. 20402.

14. NO. OF PRINTED PAGES

Order From National Technical Information Service (NTIS), Springfield, VA. 22161

15. Price 


$-$ 